\title{
Approaching Honor and Shame with Humility: Limitations to Our Current Understanding

\section{David R. Dunaetz}

Azusa Pacific University, USA

\begin{abstract}
Although honor and shame have been popular missiological themes in the last decade, there are several limitations associated with the concepts that occur in both the missiological literature and the secular anthropological, sociological, and psychological literature. The first set of limitations concerns the meaning of honor and shame. Their definitions vary greatly from author to author. Some authors consider honor and shame to be emotions internal to the individual and others consider them as a measure of one's social status, something external to the individual. Similarly, there is often no distinction made between shame and shame proneness. Their relationship with other selfconscious emotions (guilt, embarrassment, and pride) is not clear. Often the distinction between vicarious and individual shame and honor is blurred. The second set of limitations concerns our lack of understanding of how honor and shame relate to culture. Since shame dynamics exist in every culture, it is not clear what is meant by a "shame culture." Modern conceptions of culture tend to view culture as a phenomenon that is due to psychological processes within individuals, rather than external to the individual. Characteristics of cultures are described by positions on dimensions. Shame cultures are often defined as those which are more collectivistic (vs. individualistic). However, many definitions of honor and shame indicate that the dimension of cultural tightness (or uncertainty avoidance) may be just as relevant for understanding shame dynamics, and the cultural dimension of power distance may also be relevant. In light of these limitations, missiologists need to approach the concepts of honor and shame with humility.
\end{abstract}

\section{Keywords}

shame, honor, culture, emotion, status, cultural tightness, collectivism 
One of the most popular topics in missiology over the last decade has been that of honor and shame. The topic has often been framed in Eugene Nida's (1954) three-fold classification of cultures as being either shame-based, guilt-based, or fear-based. Many excellent books have been written providing insights into both western and non-western cultures, as well as tools for better understanding the biblical texts where shame plays a prominent role (Cozens, 2019; Georges, 2017; Georges \& Baker, 2016; Muller, 2000; $\mathrm{Wu}, 2019)$. The principal application of this distinction in missiological contexts concerns the presentation of the gospel: The gospel is most powerful in honor/shame societies when it is presented as a means of transforming our shame to honor, whereas an emphasis on our need for forgiveness through Christ's death because of our guilt is more effective in individualistic cultures than in collectivistic cultures.

However, a number of critiques of this trend have also appeared. Cozens (2018) argues that Nida's (1954) classification system is "an undeveloped, unsourced, and essentially offhand remark" (Cozens, 2018; p. 338). He argues that the demarcation between cultural groups is not clear and that all cultural groups use honor and shame for social control to some degree. Steffen (2020) argues that a fourth classification of cultures (purity/pollution) makes Nida's (1954) classification more complete. Merz argues (2019) that honor and shame has never been a topic appreciated in anthropology because the work of Ruth Benedict (1946), who introduced the idea of guilt-based and shame-based cultures, was so severely criticized by the Japanese whom she sought to describe and because the presuppositions underlying such classifications of culture have been rejected (cf. Brightman, 1995; Rynkiewich, 2011). Flanders (2019) presents a similar argument that missiology has drifted from contemporary anthropology in its understanding of culture, which, as Merz (2019) argues is now primarily understood as existing within individuals (i.e., psychological), not as something that exists external to the individual. Flanders (2019) presents evidence that all cultures have similar honor and shame dynamics; it is simply the honor codes of different cultures that dictate which behaviors are honored and which are shamed. Although these critiques and others (Flanders \& Mischke, 2020) are from a Christian perspective, the concepts of shame and guilt and their association with culture have also generated much controversy in the secular literature (e.g., Anolli \& Pascucci, 2005; Blum, 2008; Campos, 2007; Cohen et al., 2011; Furukawa et al., 2012; Gilmore, 1987).

The thesis of this article is that missiologists and missionaries need to respond with humility when addressing these topics, admitting that there is much that we do not know. The first set of reasons for a humble response concerns the wide range of meaning of many of the terms associated with honor and shame. The second set of reasons concerns the underlying uncertainties associated with honor and shame and their role in culture. Missiological applications of these concepts will be proposed that focus on recognizing the importance of using more precise vocabulary when discussing honor and shame dynamics, the importance of paying attention to cultural dimensions 
when describing cultures, and the importance of proclaiming the whole gospel which responds to a broad range of human needs concerning shame, guilt, and fear.

\section{Problems with the Definition and Use of the Word "Shame"}

The first major reason we should be humble when we talk about shame in missiological contexts concerns the different meanings of shame (and its antonym honor). Sometimes shame is defined as an emotion (Georges, 2017; Georges \& Baker, 2016; Sznycer \& Lukaszewski, 2019; Tangney et al., 2007), something internal to an individual, and sometimes it is defined as one's social status, something external to the individual and determined by others (Georges, 2017; Georges \& Baker, 2016). Moreover, when shame is described as an emotion, sometimes it is said to be the emotion that accompanies a loss of social status (Georges \& Baker, 2016; Sznycer et al., 2016) and other times it is said to be the emotion that accompanies self-despising (Georges, 2017).

In recent decades, shame in the English-speaking world has been closely identified with the emotion that accompanies self-despising or self-hatred, the reaction that accompanies the belief, "I am a mistake" (Georges, 2017; Lewis, 1971; Tangney et al., 1996; Tangney et al., 2007). However, shame has only been associated with this emotion since the 1970s (Blum, 2008). Shame has historically been the emotion associated with negative social evaluations and the threat of ostracism (Benedict, 1946; Blum, 2008; Sznycer \& Lukaszewski, 2019; Sznycer et al., 2016; Thigpen, 2020).

These two emotions are sometimes quite different. The historical meaning of shame, the emotion that one feels when threatened with negative social evaluation or ostracism, is experienced in all or almost all cultures (Sznycer et al., 2016). It appears to be functional in that it motivates people to maintain a favorable evaluation by others so as to maintain their membership in a community. The information threat theory of shame (Sznycer \& Lukaszewski, 2019; Sznycer et al., 2016) predicts that a person will feel shame any time there is actual, probable, or even potential negative evaluations of self by other members of the community. When people feel shame because of something they did, they change their behavior so that those observing them will not think that the qualities and traits associated with that behavior are typical of them. For example, shame may lead a person who is caught drunk to swear off alcohol, claim that this episode of drunkenness was an abnormality, deny that he or she was drunk, avoid those who caught him or her, or confess the drunkenness and begin attending Alcoholics Anonymous meetings. In each case, the response may be driven to restore the lost social status due to the drunkenness episode becoming known to others.

In contrast, shame with the more contemporary meaning of self-despising is generally considered dysfunctional (Tangney et al., 1996; Tangney et al., 2007). The origin of this meaning of shame is found in Freud's psychoanalytic view of the world and was popularized by Helen Lewis's (1971a, 1971b) work on guilt and shame (Blum, 2008; Tangney et al., 2007). In this perspective shame ("I am a mistake") is contrasted to guilt 
("I made a mistake;" Georges, 2017; McClintock, 2011); whereas guilt makes a person who has committed a transgression feel repentant, this type of shame is simply associated with self-loathing, self-isolation, denial, aggression, and psychological suffering, all of which are dysfunctional responses to a transgression (Tangney et al., 1996; Tangney et al., 2007; Tracy \& Robins, 2007).

In light of these various meanings of the word shame (loss of social status, the emotion associated with fear of social exclusion, or the emotion associated with selfdespising), we need to approach the topic with humility, seeking to clarify what we mean by shame in a given context and to not automatically apply principles associated with one type of shame to other types of shame.

\section{Shame versus Shame proneness}

Another limitation to our understanding is due to our tendency to confuse the feeling of shame and shame proneness. The feeling of shame (whether it be the fear of social exclusion or self-despising) is a state that comes and goes. In some circumstances individuals feel shame and in other circumstances they do not. In contrast, shame proneness is the tendency to experience such feelings (Cohen et al., 2011; Wolf et al., 2010). It is more or less a stable characteristic of the individual. In some circumstances, many people will feel shame and in other circumstances fewer people will feel shame. The greater one's shame proneness, the more likely a person is to feel shame when he or she violates a social norm or ethical standard, especially if the norm or standard violated is relatively minor.

Yet, at the same time, it is quite possible that a person who is high in shame proneness may experience less shame in life (especially shame in the sense of a loss of social status) than a person who is low in shame proneness. The person who is high in shame proneness may be much more motivated to avoid violating social norms than the one who is low in shame proneness.

This distinction between shame and shame proneness is important if we describe differences in cultures or classify some cultures as shame cultures. Are shame cultures where individuals experience shame frequently or are they cultures where individuals are high in shame proneness? Or are they something else? Furukawa and colleagues (2012) measured shame proneness in Japan, South Korea, and the United States, specifically the tendency to evaluate oneself negatively (the self-despising form of shame). Japanese were high in shame proneness whereas South Koreans and Americans were both low in shame proneness, a result that does not concur very well with the classification of East Asian cultures as shame cultures (Georges, 2017). To add to the confusion. South Koreans were highest in guilt proneness whereas Americans and Japanese were both low in guilt proneness. However, in all three countries, greater shame proneness in individuals was positively correlated with blaming others for one's own transgressions and feeling anger. Similarly, in all three countries, guilt proneness in individuals was positively correlated with taking responsibility for one's own 
transgressions. Such complexity should motivate us to humbly avoid over-simplistic classifications of cultures.

\section{Shame's Relationship with Other Self-Conscious Emotions}

Shame and its opposites honor and pride, along with guilt and embarrassment, are known as the self-conscious emotions (Campos, 2007; Robins et al., 2007; Tangney et al., 2007; Tracy \& Robins, 2007). In contrast to the basic emotions (e.g., anger, fear, disgust, sadness, joy, and surprise; Ekman, 1992; Ekman \& Cordaro, 2011) which tend to be focused on something external to the person, especially other people, the selfconscious emotions are focused on self. Another difference is seen from a developmental perspective. Whereas children begin to express the basic emotions at around nine months, the self-conscious emotions only appear beginning at around three years (Tracy \& Robins, 2007).

In Western contexts, the self-conscious emotions shame, guilt, and embarrassment appear to be distinct emotions (Tangney et al., 1996). Embarrassment, in contrast to shame and guilt, is typically a response to a non-moral transgression. In the fear of exclusion concept of shame, shame comes from one's actions being evaluated negatively by others, whereas guilt comes from negatively evaluating one's own actions (Benedict, 1946). In the negative self-evaluation concept of shame, shame is a response to stable attributes of the self, whereas guilt is attributed to a state of the self which led to specific behaviors. In general, in the West, a person feels shame when his or her behavior causes someone relatively close to them to experience sadness, anger, or contempt; in contrast, a person feels guilty when his or her behavior causes fear (potential hurt), disappointment, or suffering (actual hurt) in a person close to them (Campos, 2007; Wolf et al., 2010). However, in Asian contexts, the distinction between shame and guilt may be less clear (Wong \& Tsai, 2007). Because of the interdependent construal of self which characterizes collectivistic cultures (Markus \& Kitayama, 1991) the distinction between being negatively evaluated by self and being negatively evaluated by others is blurred. Words expressing shame in Chinese are sometimes translated as shame and sometimes as guilt because the two concepts are present when focusing on self in light of one's transgressions (Li et al., 2004). Yet this overlap also exists in Western cultures where proneness to shame and proneness to guilt are strongly correlated with each other (Wolf et al., 2010); people who are apt to feel guilt are also the most apt to feel shame.

In light of the strong overlap that exists between guilt and shame, especially since the nature of this overlap is influenced by culture, extreme care must be used when classifying cultures according to the role that honor and shame play within them. We must humbly admit that our biases and worldview may cloud the underlying reality.

\section{Individual and Vicarious Shame}

Sometimes honor and shame are experienced because of an individual's own 
actions, but sometimes they are experienced vicariously because of the behaviors of a member of one's ingroup (Tangney et al., 2007). This distinction between individual and vicarious honor/shame is sometimes called achieved and ascribed honor/shame (Georges \& Baker, 2016). In collectivistic cultures where one's sense of self may be defined more by the characteristics and actions of the groups to which one belongs than by one's personal characteristics and actions, vicarious shame and honor are experienced more frequently and perhaps more intensely than in individualistic cultures (Anolli \& Pascucci, 2005; Markus \& Kitayama, 1991). However, as westerners, we tend to put the emphasis on individual honor and shame. We need to be careful about how we present the gospel. It may not be correct or especially meaningful to say that Christ died on the cross because he wants to honor us as individuals (cf. Georges, 2017, p. 57). It may be more correct and more meaningful to say that Christ died because God loves us so much that he wants to adopt us into his family as his children, which transforms our shame into honor (John 3:16, Eph. 1:5). In collectivistic cultures, the vicarious honor that comes from being a member of God's family is likely to be more easily understood than any individual honor that comes from God. This is especially true because the benefits of Christ death are vicarious by nature (Isa. 53:6, I Pet. 3:18, Mark 10:45).

\section{Difficulty in Accessing Our Own Shame}

We tend to express basic emotions such as anger, joy, fear, and sadness quite easily, typically with facial expressions that are readily discernable to others (Ekman, 2007; Ekman \& Cordaro, 2011). We tend to be relatively aware of these emotions because they are so easily accessible. Shame, and perhaps honor, are less accessible. There is no specific facial expression for shame, and the typical gestures associated with shame include looking away, covering our face, and trying to hide.

In general, shame motivates us to deny our actions, remove ourselves from the situation, or hide (Tangney et al., 2007). We tend not to want to let others know of our shame and it is quite possible that we try to hide it from ourselves to protect our sense of self (Tracy \& Robins, 2007). The Cooley-Scheff Conjecture (Scheff, 1988) proposes that we as humans are almost always in either a state of shame or pride because we are continually monitoring what others are thinking of us. We feel pride or honor if we do what others approve of; we feel shame if we do what others condemn. We tend not to show these feelings to others because any indication that we sometimes behave in socially inappropriate ways would cause us to lose face. Not only do these emotions tend to be inaccessible to others, but they tend to be inaccessible to ourselves, as our behavior becomes automatically attuned to social norms (Scheff, 1988; Tangney et al., 2007; Tracy \& Robins, 2007).

This inability to detect our own emotions of shame or pride may blind us to the role that shame and pride plays in our own life and culture (Scheff, 1988; Tracy \& Robins, 2007) but may make us more aware of the role of shame and pride in other 
cultures. This may push us toward an interpretation of a culture that is neither emic nor etic, and that reflects more our inability to understand at an emotional level the sources of honor and shame in the observed culture than a difference in honor/shame dynamics between the observed culture and our own culture (Georges \& Baker, 2016; Merz, 2019). A potential blindspot such as this should once again cause us to approach an honor/guilt/fear classification of cultures with humility.

\section{Our Lack of Understanding Concerning Shame and Honor's Relationship with Culture}

It is not always clear what a "shame/honor culture" is compared to a "guilt/innocence culture" or a "fear/power culture." All cultures have honor and shame dynamics (Anolli \& Pascucci, 2005; Flanders, 2019; Furukawa et al., 2012; Sznycer et al., 2016; Wong \& Tsai, 2007), although the ways of shaming people and the effects of shame vary by culture. For example, in the United States, perhaps the paradigm of a guilt/innocence culture, publicly observable mug shots and "perp walks" are used to shame individuals regardless of their legal guilt or innocence. The studies comparing shame dynamics in India and Italy by Annoi and Pascucci (2005) and in South Korea, Japan, and the U. S. by Furukawa and colleagues (2012) indicate that differences in shame dynamics between Asian and Western cultures are not clear and consistent.

\section{Universal Shame Dynamics}

Nevertheless, shame is experienced in all cultures when a person experiences a threat of social devaluation (Sznycer et al., 2016). The emotion of shame is universally experienced by people when there is a threat of information reaching others which will devalue them in others' eyes. In this sense, shame is functional in that it motivates the person not to act in a way which would lead to social exclusion. The thought of what we would feel if we were to commit a socially unacceptable act deters us from doing it if these negative feelings outweigh the estimated benefits from committing the act.

In all cultures, there are various qualities of an individual which are socially valued (some of which are valued by God, such as trustworthiness and moral uprightness, some of which are not, such as height or beauty); the specific value put on any quality varies by culture (Sznycer \& Lukaszewski, 2019). When others believe that the person has one of the highly valued qualities, the person may feel honor or pride. When others believe that one of these qualities is not present in the person, the person may feel shame. This creates a series of universal shame dynamics (Sznycer \& Lukaszewski, 2019; Sznycer et al., 2016). The fear of experiencing shame causes people to act so that others will not think that they lack the socially valued qualities. Shame can be triggered by actual or probable devaluation. It motivates people to hide socially devaluing information from others. Similarly, shame motivates people to stop performing behaviors that are devaluing and to appease others who may be offended by 
what they have done (Keltner et al., 1997; Robertson et al., 2018; Sznycer \& Lukaszewski, 2019; Sznycer et al., 2016).

\section{The Importance of Cultural Dimensions}

Anthropology as a field has developed significantly since Nida came up with his threefold classification of cultures in 1954 (Merz, 2019). Contemporary anthropologists no longer study culture as if it were something that was "out there" and directly observable (Brightman, 1995; Rynkiewich, 2011). Rather, humans are viewed as the agent of culture which is a product of "how humans think, act, and live" (Merz, 2019, p. 13). Rather than classifying cultures into types, cultures tend now to be understood along cultural dimensions which are a measure of the degree that various traits tend to be found in individual members of the culture. Our knowledge of these cultural dimensions is limited but growing.

The most common set of cultural dimensions consists of those discovered by Geert Hofstede while studying IBM employees across 40 countries (Hofstede, 1980, 2011; Hofstede et al., 2010). The dimensions discovered included individualism/collectivism, power distance, and uncertainty avoidance. Due to the restriction of range of participants and limited data available permitting the comparison of individuals across a large number of cultures, Hofstede's initial work was quite rudimentary. However, significant progress has been made in understanding some of these dimensions, especially individualism/collectivism (Minkov et al., 2017; Santos et al., 2017) and uncertainty avoidance, now most commonly identified as cultural tightness/looseness (Dunaetz, 2019a; Gelfand et al., 2006; Gelfand et al., 2011). As our understanding of how cultures differ along various dimensions grows, we are able to better understand the reasons for how culture (including shame and honor dynamics) manifests itself in various contexts.

\section{Shame and Honor Dynamics and Cultural Dimensions}

Much that has been written on honor and shame dynamics from a Christian perspective has equated honor/shame cultures with collectivism and guilt/innocence cultures with individualism (Georges, 2017; Georges \& Baker, 2016). However, just as with an overly simple classification of cultures into type, we need to be humble when trying to associate honor/shame dynamics with a single cultural dimension. It is likely that several or all cultural dimensions may shed light on how honor/shame dynamics play out in different cultures.

Shame Dynamics and Individualism/Collectivism. The individualism/ collectivism cultural dimension focuses on how members of a culture construe their sense of self, that is, their identity (Kim et al., 1994; Markus \& Kitayama, 1991; Minkov et al., 2017). In cultures high in collectivism, one's identity is solidly founded on one's ingroup (or collectivity); the individual's sense of self is highly congruent with the perceived characteristics of one's ingroup, whether it be family, nation, or ethnicity. In 
contrast, members of individualistic cultures view themselves as unique individuals with their own traits, values, and life situations. Collectivistic cultures are characterized by strong, cohesive groups, with high levels of ingroup favoritism (Hofstede, 2011; Yamagishi et al., 1998). In contrast, individualistic cultures are characterized by weak ties between individuals and group membership is easily changed; this flexibility is associated with greater economic development which in turn leads to a lowered need for group cohesion, resulting in an upward spiral of greater levels of individualism in most modern cultures (Santos et al., 2017).

It is clear that individualism and collectivism will have an effect on honor and shame dynamics. First, as collectivistic cultures are characterized by greater cohesion and interdependence (Hofstede et al., 2010; Minkov et al., 2017), the social norms defining acceptable behavior are more uniform throughout the culture; everyone knows what shameful and honorable behavior is. In contrast, in more individualistic cultures, that which is shameful and honorable varies more from one person to another. This can be observed even within the United States. Brooklyn, Coastal California, and the South are all more collectivistic than many other parts of the U.S. (Malone et al., 2013; Vandello \& Cohen, 1999; cf. Hofstede et al., 2010). In each of these regions there is a general consensus of what is honorable and what is dishonorable (at least concerning for whom one should vote; Bloch et al., 2018), but there is certainly little consensus between these regions. In contrast, more individualistic regions of the U.S. have less uniform standards of shameful and honorable behavior (Cohen, 1996; Cohen et al., 1996; Vandello \& Cohen, 1999).

A second honor-shame dynamic associated with individualism and collectivism concerns the phenomena of vicarious shame, the shame that one feels personally when a member of one's ingroup acts in a shameful way (Georges \& Baker, 2016; Lickel et al., 2005). In collectivistic cultures, where one's identity is closely associated with group membership, vicarious shame is much more likely than in individualistic cultures where group membership is less central to one's identity.

These two phenomena, greater uniformity in standards of shameful and honorable behavior and more frequently experiencing vicarious honor and shame, may contribute to making collectivistic societies seem more focused on honor and shame than individualistic societies. However, other cultural dimensions may also contribute to honor and shame dynamics.

Shame Dynamics and Tightness/Looseness. The cultural dimension of tightness/looseness (Aktas et al., 2016; Gelfand et al., 2006; Gelfand et al., 2011), sometimes identified as Hofstede's $(1980,2011)$ dimension of uncertainty avoidance (Triandis, 2004), plays a central role in contemporary studies on cultural dimensions (Gelfand, 2018) but has received limited attention in the missiological literature (but see Dunaetz, 2019). In tight cultures, in contrast to loose cultures, violations of social norms are readily sanctioned; in loose cultures, many violations of social norms are overlooked and tolerated. Tightness/looseness is essentially the willingness of cultural members to 
inflict sanctions on others who do not abide by the culture's behavioral norms. Cultures in Asia, Africa, and especially the Middle East tend to be tighter than Cultures in the Americas and Europe (Dunaetz, 2019a; Gelfand et al., 2011; Uz, 2015). This phenomenon partially explains why it so much more difficult to become a Christian in some cultures than in others.

Cultural tightness and collectivism tend to be moderately correlated (Carpenter, 2000; Gelfand et al., 2011), but not all tight cultures are collectivistic. Germany is an example of a relatively tight country that tends to be individualistic while Brazil tends to be both loose and collectivistic (Gelfand et al., 2006). Within the U.S., Oregon and New Hampshire both tend to be loose and individualistic while South Carolina and Mississippi tend to be both tight and collectivistic; however, California and Hawaii tend to be loose and collectivistic while Kansas and Ohio tend to be tight and individualistic (Harrington \& Gelfand, 2014).

Cultural tightness seems likely to be related to honor/shame dynamics via the phenomenon of shame proneness, the tendency to feel shame if one were to violate a social norm. In tight cultures, such violations are more likely to be punished than in loose cultures, increasing the shame proneness of individuals who live in tight cultures. Thus, members of collectivistic cultures that are loose (e.g., Brazil or California) may be less prone to experience shame than members of collectivistic cultures that are tight (Saudi Arabia or Alabama). This can explain some of the variation in shame/honor dynamics beyond what collectivism/individualism can explain, motivating us to be humble when we link shame and honor to collectivistic cultures.

Shame Dynamics and Power Distance. Another cultural dimension that may influence shame dynamics is power distance (Hofstede, 2011; Hofstede et al., 2010), the strength of social hierarchies that reflect the power that one person has over another. In countries with high power distance (e.g., France and many countries in Southeast Asia and Latin America), large inequalities in power between people based on social status is accepted and expected. Countries low in power distance (e.g., Scandinavia) value egalitarianism. In high power distance cultures (compared to low power distance cultures), shaming may be more visible because when a power holder shames an individual, his or her power is viewed as legitimate and credible. Daniels (2015) found that the pain of being shamed by a superior was greater when people valued power distance. Thus in high power distance countries, social control by those in authority is likely greater than in low power distance countries because the common person may have a greater fear of being exposed (Sznycer et al., 2016). In contrast, in low power distance cultures, shame and despising are more likely to come from self than from others, resulting in less pressure to conform socially and less effort spent trying to hide one's violations of social norms.

Because cultures are so complex, we need to humbly admit that some shame dynamics may play out in very different ways in different cultures. The individualism/collectivism dimension is not the only cultural dimension to influence 
shame dynamics. Cultural tightness/looseness, power distance, and other dimensions, conceivably many other dimensions, will influence these dynamics, perhaps in quite unforeseen ways.

\section{Applications and Conclusion}

In light of the uncertainty and complexity of what humans experience concerning honor and shame, we as missionaries and leaders need to humbly admit our limited understanding of the shame and honor that members of other cultures experience. We must continue to do research on the topic and strive to better understand the range and patterns of human experience. In the meantime, there are several specific efforts we can attempt to undertake.

\section{Try to be clear and specific when we use honor and shame} vocabulary. We have seen that shame can be internal (an emotion) or external (low social status as perceived by others). As an emotion, shame is sometimes viewed as the feelings that one has when social status is lost and sometimes as the feelings that are associated with self-despising. Similar contrasts can be made concerning honor. All of these forms of shame are very different from one another and should not be confounded or confused. In order to be credible as missionaries and leaders (Dunaetz, 2019b, 2019c) we must demonstrate expertise in the subjects about which we speak. Using precise vocabulary with clear meanings is a step in that direction.

\section{Use Multiple Cultural Dimensions to Describe Cultures. Many} missionaries come from Western cultures that are high in individualism, low in tightness, and low in power distance. It is easy to classify all other cultures into just one or two categories: collectivistic, honor/shame, power/fear, and so on. However, cultural dimensions may provide a much better way of capturing the variation that exists among cultures. Missionaries and missiologists should become more familiar with these dimensions, and even discover new ones, to better describe one culture relative to others and to understand how culture relates to the various cognitive, behavioral, and affective phenomena that occur within a culture. Cultures are very complex, and we need to humbly discover new ways and develop new tools to better understand them.

3. Proclaim the Whole Gospel. The primary reason that the honor and shame paradigm has rightfully become so popular in missiological circles is that it has produced a framework that seems to better communicate the gospel to many nonWestern audiences than a traditional presentation that emphasizes our guilt and the forgiveness of sins through Christ's death. Using biblical concepts and principles concerning honor and shame, as well as power and fear, communicates aspects of the gospel that better respond to people's felt needs in many cultures. Yet the multifaceted gospel of the New Testament (or the 3-D gospel; Georges, 2017) responds to all people's needs in all cultures, needs which are due to shame, guilt, and fear. We should avoid thinking that one specific emphasis is the key to reaching everyone within a culture, but 
to proclaim the whole gospel to everyone where we can, the gospel which responds to all human needs due to shame, guilt, and fear. Some individuals will come to Christ to be relieved of their shame, some for the forgiveness of sin, and some to be delivered from their fears. But it is quite possible that even more will come for some combination of these needs. And certainly, as these young believers grow in their understanding of the gospel and in their experience with Christ, they will discover more and more that his death and resurrection is God's solution to all their shame, all their guilt, and all their fears.

\section{References}

Aktas, M., Gelfand, M. J., \& Hanges, P. J. (2016). Cultural tightness-looseness and perceptions of effective leadership. Journal of Cross-Cultural Psychology, 47(2), 294-309.

Anolli, L., \& Pascucci, P. (2005). Guilt and guilt-proneness, shame and shame-proneness in Indian and italian young adults. Personality and Individual Differences, 39(4), 763-773.

Benedict, R. (1946). The chrysanthemum and the sword; patterns of japanese culture. Houghton Mifflin.

Bloch, M., Buchanan, L., Katz, J., \& Quealy, K. (2018). An extremely detailed map of the 2016 election. The New York Times. https://www.nytimes.com/interactive/2018/upshot/election-2016-votingprecinct-maps.html

Blum, A. (2008). Shame and guilt, misconceptions and controversies: A critical review of the literature. Traumatology, 14(3), 91-102.

Brightman, R. (1995). Forget culture: Replacement, transcendence, relexification. Cultural Anthropology, $10(4), 509-546$.

Campos, J. J. (2007). Foreward. In J. L. Tracy, R. W. Robins, \& J. P. Tangney (Eds.), The self-conscious emotions: Theory and practice (pp. ix-xii). Guilford Press.

Carpenter, S. (2000). Effects of cultural tightness and collectivism on self-concept and causal attributions. Cross-cultural research, 34(1), 38-56.

Cohen, D. (1996). Law, social policy, and violence: The impact of regional cultures. Journal of Personality and Social Psychology, 70, 961-978.

Cohen, D., Nisbett, R. E., Bowdle, B. F., \& Schwarz, N. (1996). Insult, aggression, and the southern culture of honor: An "experimental ethnography". Journal of Personality and Social Psychology, 70(5), 945-960.

Cohen, T. R., Wolf, S. T., Panter, A. T., \& Insko, C. A. (2011). Introducing the gasp scale: A new measure of guilt and shame proneness. Journal of Personality and Social Psychology, 100(5), 947-966.

Cozens, S. (2018). Shame cultures, fear cultures, and guilt cultures: Reviewing the evidence. International Bulletin of Mission Research, 42(4), 326-336.

Cozens, S. (2019). Looking shame in the eye: A path to understanding, grace and freedom. Inter-Varsity Press UK.

Daniels, M. A. (2015). Shame as an alternate mechanism for the abusive supervision-performance relation and the role of power distance values. Bowling Green State University.

Dunaetz, D. R. (2019a). Cultural tightness-looseness: Its nature and missiological applications. Missiology, 47(4), 410-421.

Dunaetz, D. R. (2019b). Fundamentals of missionary leadership: What we know with reasonable confidence. Evangelical Missions Quarterly. 
Dunaetz, D. R. (2019c). Missionary credibility: Characteristics of the messenger that make the message more persuasive. In D. R. Dunaetz (Ed.), God first: Essays in honor of Michael M. Whyte and Gary D. Lemaster (pp. 187-199). Martel Press.

Ekman, P. (1992). Are there basic emotions? Psychological Review, 99(3), 550-553.

Ekman, P. (2007). Emotions revealed: Recognizing faces and feelings to improve communication and emotional life (Rev. ed.). Henry Holt Company.

Ekman, P., \& Cordaro, D. (2011). What is meant by calling emotions basic? Emotion Review, 3(4), 364370.

Flanders, C. L. (2019). There is no such thing as "honor" or "honor cultures". In C. L. Flanders (Ed.), Devoted to Christ: Missiological reflections in honor of sherwood g. Lingenfelter (pp. 145-165). Pickwick Publications.

Flanders, C. L., \& Mischke, W. (Eds.). (2020). Honor, shame, and the gospel: Reframing our message and ministry. William Carey Publishing.

Furukawa, E., Tangney, J. P., \& Higashibara, F. (2012). Cross-cultural continuities and discontinuities in shame, guilt, and pride: A study of children residing in japan, korea and the USA. Self and Identity, 11(1), 90-113.

Gelfand, M. J. (2018). Rule makers, rule breakers: How culture wires our minds, shapes our nations, and drives our differences. Scribner.

Gelfand, M. J., Nishii, L. H., \& Raver, J. L. (2006). On the nature and importance of cultural tightnesslooseness. Journal of Applied Psychology, 91(6), 1225-1244.

Gelfand, M. J., Raver, J. L., Nishii, L. H., Leslie, L. M., Lun, J., Lim, B. C., Duan, L., Almaliach, A., Ang, S., \& Arnadottir, J. (2011). Differences between tight and loose cultures: A 33-nation study. Science, 332(6033), 1100-1104.

Georges, J. (2017). The $3 d$ gospel: Ministry in guilt, shame, and fear cultures. Timē Press.

Georges, J., \& Baker, M. D. (2016). Ministering in honor-shame cultures: Biblical foundations and practical essentials. InterVarsity Press.

Gilmore, D. D. (1987). Honor and shame and the unity of the Mediterranean (Vol. 22). American Anthropological Association.

Harrington, J. R., \& Gelfand, M. J. (2014). Tightness-looseness across the 50 United States. Proceedings of the National Academy of Sciences, 111(22), 7990-7995.

Hofstede, G. (1980). Culture's consequences: National differences in thinking and organizing. Sage.

Hofstede, G. (2011). Dimensionalizing cultures: The hofstede model in context. Online readings in psychology and culture, 2(1), 1-26.

Hofstede, G., Hofstede, G. J., \& Minkov, M. (2010). Cultures and organizations: Software of the mind (3rd ed.). McGraw Hill.

Keltner, D., Young, R. C., \& Buswell, B. N. (1997). Appeasement in human emotion, social practice, and personality. Aggressive Behavior: Official Journal of the International Society for Research on Aggression, 23(5), 359-374.

Kim, U. E., Triandis, H. C., Kâğitçibaşi, Ç. E., Choi, S.-C. E., \& Yoon, G. E. (1994). Individualism and collectivism: Theory, method, and applications. Sage Publications.

Lewis, H. B. (1971). Shame and guilt in neurosis. Psychoanalytic review, 58(3), 419-438.

Li, J., Wang, L., \& Fischer, K. (2004). The organisation of Chinese shame concepts? Cognition and Emotion, 18(6), 767-797.

Lickel, B., Schmader, T., Curtis, M., Scarnier, M., \& Ames, D. R. (2005). Vicarious shame and guilt. Group Processes \& Intergroup Relations, 8(2), 145-157.

Malone, B., Hasan, S., Sanni, A., \& Reilly, J. (2013). Mismatch of cultural dimensions in an urban medical educational environment. Journal of Biomedical Education, 2013, 1-7.

Markus, H. R., \& Kitayama, S. (1991). Culture and the self: Implications for cognition, emotion, and motivation. Psychological Review, 98(2), 224-253. 
McClintock, K. A. (2011). Shame-less lives, grace-full congregations. Rowman \& Littlefield.

Merz, J. (2019). The culture problem: How the honor/shame issue got the wrong end of the anthropological stick. Missiology, Advance online publication. https://doi.org/10.1177/o091829619887179

Minkov, M., Dutt, P., Schachner, M., Morales, O., Sanchez, C., Jandosova, J., Khassenbekov, Y., \& Mudd, B. (2017). A revision of Hofstede's individualism-collectivism dimension: A new national index from a 56-country study. Cross Cultural \& Strategic Management, 24(3), 386-404.

Muller, R. (2000). Honor and shame: Unlocking the door. Xlibris.

Nida, E. A. (1954). Customs and cultures: Anthropology for Christian missions. Harper \& Brothers.

Robertson, T. E., Sznycer, D., Delton, A. W., Tooby, J., \& Cosmides, L. (2018). The true trigger of shame: Social devaluation is sufficient, wrongdoing is unnecessary. Evolution and Human Behavior, 39(5), 566-573.

Robins, R. W., Noftle, E. E., \& Tracy, J. L. (2007). Assessing self-conscious emotions. In J. L. Tracy, R. W. Robins, \& J. P. Tangney (Eds.), The self conscious emotions (pp. 443-467). Guilford.

Rynkiewich, M. A. (2011). Do we need a postmodern anthropology for mission in a postcolonial world? Mission Studies, 28(2), 151-169.

Santos, H. C., Varnum, M. E. W., \& Grossmann, I. (2017). Global increases in individualism. Psychological Science, 28(9), 1228-1239.

Scheff, T. J. (1988). Shame and conformity: The deference-emotion system. American Sociological Review, 53(3), 395-406.

Steffen, T. (2020). A clothesline theology for the word: How a value-driven grand narrative of scripture can frame the gospel. In C. L. Flanders \& W. Mischke (Eds.), Honor, shame, and the gospel: Reframing our message and ministry (pp. 37-56). William Carey Publishing.

Sznycer, D., \& Lukaszewski, A. W. (2019). The emotion-valuation constellation: Multiple emotions are governed by a common grammar of social valuation. Evolution and Human Behavior, 4O(4), 395-404.

Sznycer, D., Tooby, J., Cosmides, L., Porat, R., Shalvi, S., \& Halperin, E. (2016). Shame closely tracks the threat of devaluation by others, even across cultures. Proceedings of the National Academy of Sciences, 113(10), 2625-2630.

Tangney, J. P., Miller, R. S., Flicker, L., \& Barlow, D. H. (1996). Are shame, guilt, and embarrassment distinct emotions? Journal of Personality and Social Psychology, 7o(6), 1256-1269.

Tangney, J. P., Stuewig, J., \& Mashek, D. J. (2007). What's moral about the self-conscious emotions. In J. L. Tracy, R. W. Robins, \& J. P. Tangney (Eds.), The self-conscious emotions: Theory and research (pp. 21-37). Guillford.

Thigpen, L. (2020). The dark side of orality. In C. L. Flanders \& W. Mischke (Eds.), Honor, shame, and the gospel: Reframing our message and ministry (pp. 117-126). William Carey Publishing.

Tracy, J. L., \& Robins, R. W. (2007). The self in self-conscious emotions. In J. L. Tracy, R. W. Robins, \& J. P. Tangney (Eds.), The self-conscious emotions: Theory and research (pp. 3-20). Guilford Press.

Triandis, H. C. (2004). The many dimensions of culture. Academy of Management Perspectives, 18(1), 88-93.

Uz, I. (2015). The index of cultural tightness and looseness among 68 countries. Journal of CrossCultural Psychology, 46(3), 319-335.

Vandello, J. A., \& Cohen, D. (1999). Patterns of individualism and collectivism across the United States. Journal of Personality and Social Psychology, 77(2), 279-292.

Wolf, S. T., Cohen, T. R., Panter, A. T., \& Insko, C. A. (2010). Shame proneness and guilt proneness: Toward the further understanding of reactions to public and private transgressions. Self and Identity, 9(4), 337-362.

Wong, Y., \& Tsai, J. (2007). Cultural models of shame and guilt. In J. L. Tracy, R. W. Robins, \& J. P. Tangney (Eds.), The self-conscious emotions: Theory and research (pp. 209-223). Guilford. 
Wu, J. (2019). Reading Romans with eastern eyes: Honor and shame in paul's message and mission. InterVarsity Press.

Yamagishi, T., Jin, N., \& Miller, A. S. (1998). In-group bias and culture of collectivism. Asian Journal of Social Psychology, 1(3), 315-328.

\section{Author Biography}

David R. Dunaetz (PhD, Claremont Graduate University) is Associate Professor of Leadership and Organizational Psychology at Azusa Pacific University (California, USA) and a former church planting missionary to France. His research focuses on interpersonal processes in Christian contexts. 